\title{
Dupilumab side effect in a patient with atopic dermatitis: a case report study
}

This article was published in the following Dove Press journal:

Biologics: Targets and Therapy

\author{
Sakhar S Albader' \\ Abdulmajeed A Alharbi ${ }^{2}$ \\ Rakan F Alenezi \\ Fahad M Alsaif ${ }^{3}$ \\ 'College of Medicine, King Saud \\ University, Riyadh, Saudi Arabia; ${ }^{2}$ College \\ of Medicine, Alqassim University, Qassim, \\ Saudi Arabia; ${ }^{3}$ Division of Dermatology, \\ College of Medicine, King Saud \\ University, Riyadh, Saudi Arabia
}

\begin{abstract}
Atopic dermatitis (eczema) is a common chronic disease that is described as severe itching associated with recurrent eczematous lesions. In 2017 the US Food and Drug Administration approved dupilumab for treatment of adults with moderate to severe atopic dermatitis not well controlled with topical therapies or when other therapies are inadvisable. Dupilumab is a monoclonal antibody that inhibits interleukin-4 (IL-4) and IL-13 signaling by specifically binding to the IL-4R-alpha subunit shared by the IL- 4 and IL-13 receptor complexes. There are many adverse effects reported after dupilumab therapy; commonly reported adverse effects include local injection site reactions, conjunctivitis, headache, and nasopharyngitis. Some adverse effects are rare, eg, alopecia areata and cicatricial extropion. We report a new case of a 28 -year-old female who experienced face and neck rash after dupilumab injection.
\end{abstract}

Keywords: atopic dermatitis, dupilumab, eczema, adverse effect

\section{Introduction}

Dupixent (dupilumab; Regeneron Pharmaceuticals, Inc., Eastview, NY, USA)is a monoclonal antibody that inhibits interleukin-4 (IL-4) and IL-13 signaling by specifically binding to the IL-4R-alpha subunit shared by the IL-4 and IL-13 receptor complexes. ${ }^{1,2}$ Dupilumab treatment has led to significant improvements in treating skin lesions and in patients' health-related quality of life (HRQoL). ${ }^{2}$ Multiple clinical trials and meta-analyses have shown satisfactory outcomes after dupilumab therapy.

A new case study reported in October 2018 showed hair regrowth in a patient with long-standing alopecia totalis after using dupilumab. ${ }^{3,4}$

Adverse effects after treating patients with dupilumab have been reported. Commonly observed adverse events include local injection site reactions, conjunctivitis, headache, and nasopharyngitis. ${ }^{5}$ Extremely rare reported side effects include alopecia areata and cicatricial extropion. ${ }^{3,6}$ Overall, dupilumab has clinical advantages over other immunotherapeutic agents, such as omalizumab foratopic dermatitis (AD) patients. ${ }^{7,8}$ A recently published case report presents a case with moderate to severe AD who developed a facial rash after treatment with dupilumab which was not observed before in the literature. ${ }^{9}$ We present a similar rash presentation in a patient treated with dupilumab for AD in dermatology clinic at King Khaled University Hospital.

\section{Case presentation}

A 28-year-old married lady who had AD since childhood came to the dermatology clinic at King Khaled University Hospital complaining of severe itchy erythematous patches
Correspondence: Sakhar S Albader

College of Medicine, King Saud University,

Saudi Arabia

Tel +966554667745

Email Sakalbader@gmail.com 
that started on the limbs and progressed to the trunk since childhood but which had got worse over the past 8-10 years.

She was initially started on cyclosporine $20 \mathrm{mg}$ BID 2 months previously, but the patient reported worsening in the symptoms and no improvement. After that, we started her on cyclosporine $100 \mathrm{mg}$ BID (200 mg/day) with methotrexate reaching a maximum dose of $20 \mathrm{mg}$ q1wk where she reported $60 \%$ improvement since the previous visit. After that, she reported a flare up again and thus we started her on dupilumab.

The patient was started on dupilumab for 4 months duration $300 \mathrm{mg}$ q2wk as she noticed redness in the face (Figure 1) and neck (Figure 2) $4 \mathrm{~h}$ after the injection and resolving spontaneously after 2 days. She noted that the redness developed after every single injection simultaneously with no appearing and fading episodes; however, the rash became scaly in appearance before resolving.

It was not related to sun exposure as it occurred when the patient was at home. She also gave the history of pain and warmth over the area of redness which was rated as 7/10 in severity. There was no fever, itching, or swollen lips or eyelids.

She was applying hydroxyzine and mometasone furoate cream BID for 3 days whenever she had the episode over the affected areas and it faded after 2 days. On examination there was a non-pruritic skin rash over the cheeks and neck, no palpable lymph nodes or hepatosplenomegaly.

The laboratory workup was unremarkable which showed negative antinuclear antibody (ANA), and normal erythrocyte sedimentation rete which was $21 \mathrm{~mm} / \mathrm{h}$.

A

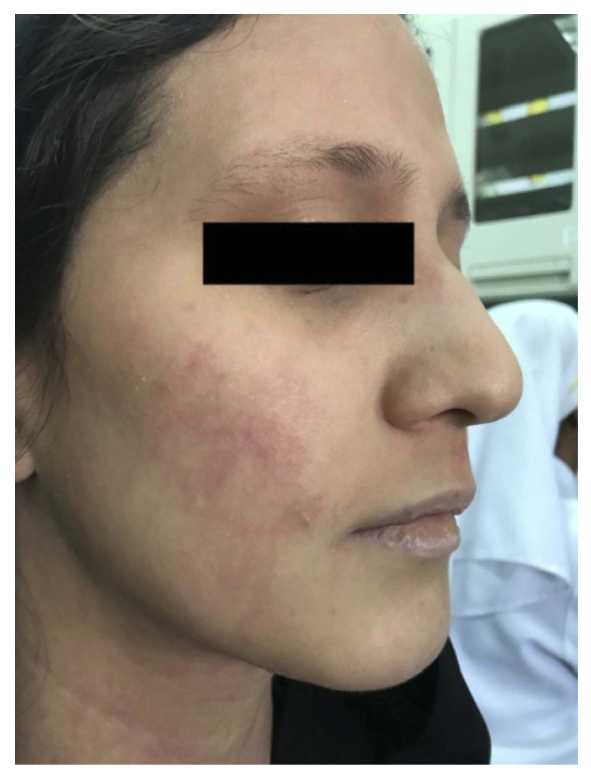

\section{Discussion}

The US Food and Drug Administration has approved dupilumab injection to treat adults with moderate-tosevere eczema (AD) not well controlled with topical therapies or when other therapies are inadvisable.

Dupilumab is safe and effective as was established in three placebo-controlled clinical trials with a total of 2,119 adult participants with moderate-to-severe AD not adequately controlled by topical medications. Overall, participants who received dupilumab achieved greater response, defined as clear or almost clear skin, and experienced a reduction in itch after 16 weeks of treatment.

A meta-analysis was done in January 2018 among eight randomized controlled trials (RCTs) which showed that patients treated with dupilumab experienced a higher risk of injection-site infection (13.2\%) than the patients treated with placebo $(6.5 \%)$, and they found that conjunctivitis occurred more frequently in patients treated with dupilumab than the placebo group, unlike previous studies which showed an equal frequency in dupilumab group and placebo-treated patients with asthma and chronic sinusitis, which could indicate that dupilumab exerts a different mechanistic outcomes in asthma and chronic sinusitis than AD. ${ }^{10-12}$ There was also a higher incidence of headache in dupilumab-treated patients than placebo-treated patients but unfortunately the mechanism is not clear and require further research. ${ }^{13,14}$

B

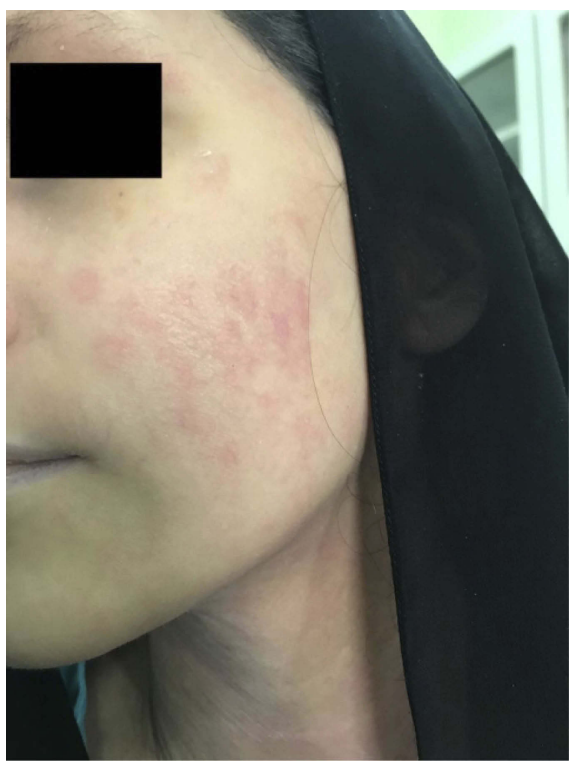

Figure I Erythematous slightly edematous patch over the cheek (A) and chin (B). 


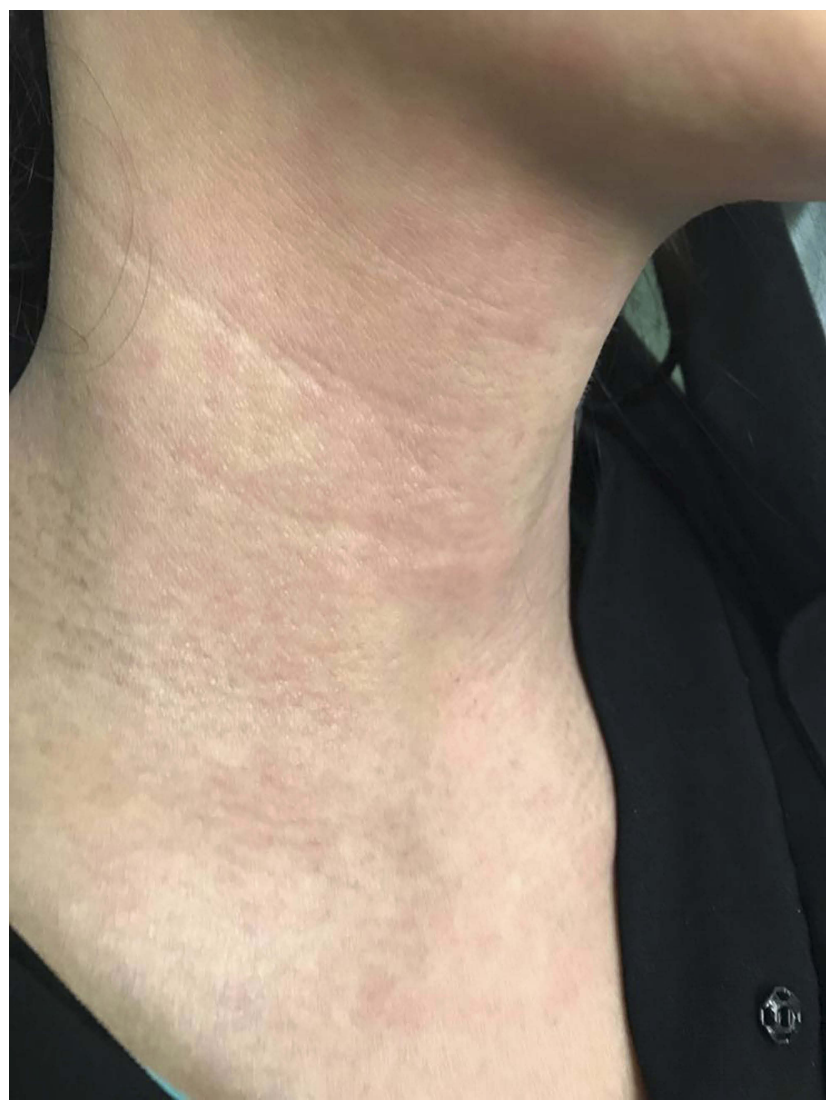

Figure 2 Multiple erythematous patches over the neck without scales.

Regarding the other infections, eg, herpes simplex, upper respiratory tract infection, and urinary tract infection, it was the same in both groups, which suggests that dupilumab does not affect the immunity against the invasion of microorganisms. ${ }^{10}$

So, to our knowledge, this manifestation of recurrent, onand-off facial and neck rash that occurred after each dupilumab injection was not observed previously in the literature, unlike Dalia et al's study where the skin rash was persistent all over the period of treatment. ${ }^{9}$ We have informed the company and producer of dupilumab about this new side effect. The cause of this new side effect is not clear. However, we hypothesize that possible etiologies should be considered, including onset of new contact dermatitis, a reaction to commensal organisms, such as pityrosporum, and onset of an autoimmune condition. We are presenting this case to raise clinical knowledge of this possible new adverse effect. We would also like to find out if other physicians have faced this issue and how they have dealt with it.

\section{Abbreviation list}

$\mathrm{AD}$, atopic dermatitis.

\section{Ethics}

Written informed consent has been provided by the patient to have the case details and any accompanying images published. No institutional approval was required to publish the case details.

\section{Disclosure}

The authors report no conflicts of interest in this work.

\section{References}

1. Eshtiaghi P, Gooderham MJ. Dupilumab: an evidence-based review of its potential in the treatment of atopic dermatitis. Core Evid. 2018;13:13. doi:10.2147/CE.S133661

2. Simpson EL. Dupilumab improves general health-related quality-oflife in patients with moderate-to-severe atopic dermatitis: pooled results from two randomized, controlled phase 3 clinical trials. Dermatol Ther. 2017;7(2):243-248. doi:10.1007/s13555-017-0181-6

3. Mitchell K, Levitt J. Alopecia areata after dupilumab for atopic dermatitis. JAAD Case Rep. 2018;4(2):143-144. doi:10.1016/j. jdcr.2017.11.020

4. Penzi LR, Yasuda M, Manatis-Lornell A, Hagigeorges D, Senna MM. Hair regrowth in a patient with long-standing alopecia totalis and atopic dermatitis treated with dupilumab. JAMA Dermatol. 2018;154 (11). doi:10.1001/jamadermatol.2018.2976

5. Lee JH, Son SW, Cho SH. A comprehensive review of the treatment of atopic eczema. Allergy Asthma Immunol Res. 2016;8(3):181-190. doi:10.4168/aair.2016.8.3.18

6. Barnes AC, Blandford AD, Perry JD. Cicatricial ectropion in a patient treated with dupilumab. Am J Ophthalmol Case Rep. 2017;7:120-122. doi:10.1016/j.ajoc.2017.06.017

7. Lane JE, Cheyney JM, Lane TN, Kent DE, Cohen DJ. Treatment of recalcitrant atopic dermatitis with omalizumab. J Am Acad Dermatol. 2006;54(1):68-72. doi:10.1016/j.jaad.2005.09.030

8. Krathen RA, Hsu S. Failure of omalizumab for treatment of severe adult atopic dermatitis. J Am Acad Dermatol. 2005;53(2):338-340. doi:10.1016/j.jaad.2005.02.014

9. Dalia Y, Marchese Johnson S. First reported case of facial rash after dupilumab therapy. Pract Dermatol. 2018;4. doi:10.1016/j. jaad.2005.02.014

10. Ou Z, Chen C, Chen A, Yang Y, Zhou W. Adverse events of dupilumab in adults with moderate-to-severe atopic dermatitis: a meta-analysis. Int Immunopharmacol. 2018;54:303-310. doi:10.1016/j.intimp.2017.11.031

11. Wenzel S, Ford L, Pearlman D, et al. Dupilumab in persistent asthma with elevated eosinophil levels. $N$ Engl $J$ Med. 2013;368 (26):2455-2466. doi:10.1056/NEJMoa1304048

12. Bachert C, Mannent L, Naclerio RM, et al. Effect of subcutaneous dupilumab on nasal polyp burden in patients with chronic sinusitis and nasal polyposis: a randomized clinical trial. Jama. 2016;315 (5):469-479. doi:10.1001/jama.2015.19330

13. Simpson EL, Bieber T, Guttman-Yassky E, et al. Two phase 3 trials of dupilumab versus placebo in atopic dermatitis. $N$ Engl J Med. 2016;375(24):2335-2348. doi:10.1056/NEJMoa1610020

14. Blauvelt A, de Bruin-Weller M, Gooderham M, et al. Long-term management of moderate-to-severe atopic dermatitis with dupilumab and concomitant topical corticosteroids (LIBERTY AD CHRONOS): a 1-year, randomised, double-blinded, placebo-controlled, phase 3 trial. Lancet. 2017;389(10086):2287-2303. doi:10.1016/S01406736(17)31191-1 


\section{Publish your work in this journal}

Biologics: Targets and Therapy is an international, peer-reviewed journal focusing on the patho-physiological rationale for and clinical application of Biologic agents in the management of autoimmune diseases, cancers or other pathologies where a molecular target can be identified. This journal is indexed on PubMed Central, CAS, EMBase,
Scopus and the Elsevier Bibliographic databases. The manuscript management system is completely online and includes a very quick and fair peer-review system, which is all easy to use. Visit http://www.dovepress.com/testimonials.php to read real quotes from published authors.

Submit your manuscript here: https://www.dovepress.com/biologics-targets-and-therapy-journal 